\title{
Ventilation-induced lung injury exists in spontaneously breathing patients with acute respiratory failure: No
}

\author{
Massimo Antonelli* (D)
}

๑ 2016 Springer-Verlag Berlin Heidelberg and ESICM

\section{Introduction}

Conflicting data have been published in regard to the beneficial or detrimental effect of spontaneous breathing (SB) compared with controlled mechanical ventilation (CMV) during acute respiratory insufficiency $[1,2]$.

Spontaneous breathing (SB) has been shown to have several beneficial effects such as the improved ventilation-perfusion matching, decreased muscle atrophy and decreased ventilator-induced lung injury (VILI) $[3,4]$.

Spontaneous breathing during airway pressure release ventilation (APRV) redistributes ventilation and aeration to dependent, usually well-perfused, lung regions close to the diaphragm, and may thereby contribute to improved arterial oxygenation. Spontaneous breathing also counters cyclic collapse, which is a risk factor for ventilationassociated lung injury [5].

However, there is experimental evidence that SB can also cause or worsen lung injury during mechanical ventilation $[6,7]$ through mechanisms that include negative intrathoracic and increased transalveolar pressure with lack of control of tidal volume (VT), ventilation inhomogeneity and cyclic and static overinflation [8].

In animals with mild lung injury, spontaneous breathing was beneficial to lung recruitment; however, in animals with severe lung injury, spontaneous breathing could worsen lung injury, and muscle paralysis might be more protective by preventing injuriously high transpulmonary pressure and high driving pressure [9].

*Correspondence: massimo.antonelli@unicatt.it

Agostino Gemelli University Hospital, Università Cattolica del Sacro Cuore, Rome, Italy

For contrasting viewpoints, please go to doi:10.1007/s00134-016-4483-4 and doi:10.1007/s00134-016-4645-4.

\section{Physiological considerations}

One of the major determinants of the VILI is considered the transpulmonary pressure

$$
P_{\mathrm{L}}=P_{\mathrm{ao}}-P_{\mathrm{pl}} \text {, }
$$

where $P_{\mathrm{L}}$ is the difference between the pressure at the airway opening and the pleural or oesophageal pressure (used as a surrogate of the pleural pressure).

During SB the airway pressure $\left(P_{\mathrm{aw}}\right)$ is lower than during CMV, but this does not necessarily translate into a lower pressure across the lung (i.e. a lower $P_{\mathrm{L}}$ ).

The total $P_{\mathrm{L}}$ has two components: (a) the pressure generated to overcome the resistance to airflow between the airway opening and the alveoli, and (b) the pressure needed to expand the terminal airways (i.e. the transalveolar pressure). Only the transalveolar pressure, which equals the product of lung elastance and volume, is dissipated across the alveolus and is usually considered to cause VILI [10].

Instead of the absolute value of transpulmonary pressures some investigators identify the lung stress with the variation of the transpulmonary pressure between end inspiration and end expiration, obtained during occlusion manoeuvres. All these manoeuvres are quite complicated to perform while patients are breathing spontaneously, especially under pressure support ventilation (PSV), and their validity is called into question.

Evaluating the clinical outcome of patients with lung injury and mild to moderate ARDS receiving various levels of PSV, followed by a phase of CMV, Bellani and collaborators [10] recently demonstrated that in intubated patients, under similar conditions of flow and volume, transpulmonary pressure change is similar between CMV and PSV.

In a severe ARDS animal model, optimizing positive end-expiratory pressure versus low positive end-expiratory pressure (PEEP; set after lung recruitment) may reverse the harmful effects of spontaneous breathing,

\section{自 Springer}



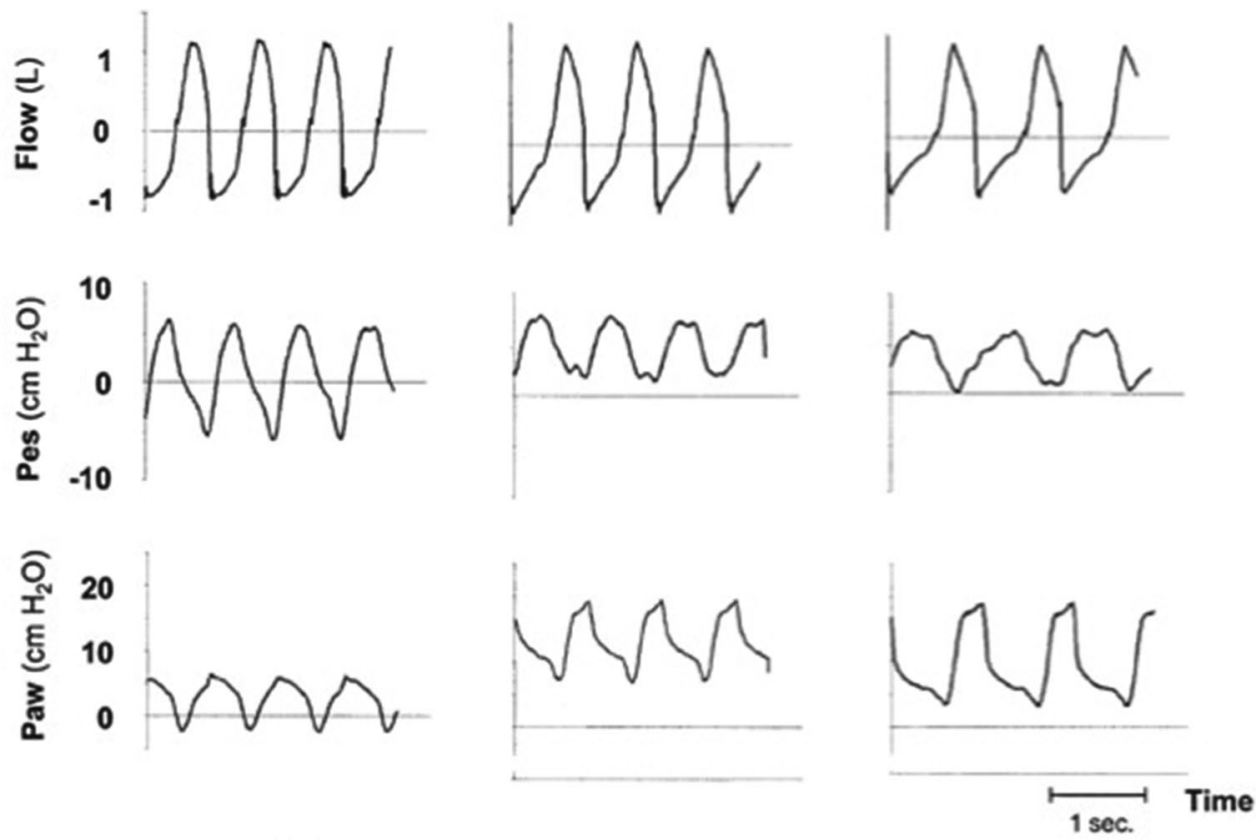

Initial
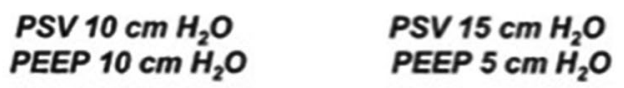

Fig. 1 Flow, oesophageal pressure $\left(P_{\text {es }}\right)$ and airway pressure tracing in a patient under spontaneous breathing (initial), pressure support (PSV) $10 \mathrm{cmH}_{2} \mathrm{O} /$ PEEP $10 \mathrm{cmH}_{2} \mathrm{O}$, and PSV $15 \mathrm{cmH}_{2} \mathrm{O}$ and PEEP $5 \mathrm{cmH}_{2} \mathrm{O}$. PSV periods were associated with greater flows and decreased $P$ es Swings. Modified from L'Her [12]

when present, by reducing inspiratory effort, pendelluft and tidal recruitment [11].

However, obtaining reliable physiological measurements in patients under noninvasive ventilation (NIV) or spontaneously breathing without an endotracheal tube is extremely difficult and there is a substantial lack of data. Under these conditions the measurement cannot be reliably achieved through the conventional manoeuvres.

The only study that reports some interesting physiological measurements was the one published by L'Her et al. [12]. These authors in a prospective, crossover, physiologic study conducted in 10 spontaneously breathing patients with acute lung injury and a $\mathrm{PaO}_{2} / \mathrm{FiO}_{2}$ below 300-200 showed that noninvasive pressure support (NIVPS) of $10-15 \mathrm{cmH}_{2} \mathrm{O}$ above a PEEP of $5-10 \mathrm{cmH}_{2} \mathrm{O}$ were the best combinations to reduce the inspiratory muscle effort, oesophageal pressure and dyspnoea and improve oxygenation.

Of note, the respiratory rate decreased significantly as well as the depth of the inspiratory effort represented by the significant swing reduction of the oesophageal pressure (Fig. 1). Making an extrapolation from the values and graphs reported in the paper, a rough estimation of the transpulmonary pressure gives an approximate value of $5-7 \mathrm{cmH}_{2} \mathrm{O}$ which is in a safe range for the pulmonary stress, even though tidal volumes were often above $6 \mathrm{ml} / \mathrm{kg}$ body weight.

\section{Clinical considerations}

What happens in the clinical setting and what is the outcome when ARDS patients spontaneously breathe without an endotracheal tube? Data from various studies have shown some benefits. Noninvasive ventilation and SB appear as efficient as the invasive mechanical ventilation in ameliorating gas exchanges and reducing complications in hypoxemic patients [13]. In a recent real-life multicentre survey on 2813 patients who developed ARDS on day 1 or 2 after ICU admission, 30\% were on spontaneous ventilation modes and $436(15 \%)$ were treated with NIV as first-line intervention [14]. Of them $300(69 \%)$ remained on NIV and were in large part successful. When NIV is successful the mortality rate of ARDS patients might be below $10 \%$ [15]. In a recent randomised controlled trial (RCT) conducted on 83 ARDS patients, treatment with helmet NIV in comparison to standard facial mask-NIV resulted in a significant reduction of intubation rates and a statistically significant reduction in 90-day mortality with helmet NIV [16]. In an RCT on 293 patients with hypoxemic respiratory failure following abdominal surgery, the use of NIV compared with standard oxygen therapy reduced the risk of tracheal reintubation within 7 days [17]. In another recent trial on 312 patients with respiratory failure, approximately $80 \%$ of them had bilateral pulmonary infiltrates and $\mathrm{PaO}_{2} / \mathrm{FiO}_{2}$ below 200; all were on 
SB and their mortality rate never exceeded $30 \%$ regardless of the use of NIV or high flow oxygen therapy [18]. Among 374 immunocompromised patients with hypoxemic acute respiratory failure randomized to receive high or low flow oxygen therapy and NIV, the vast majority had $\mathrm{PaO}_{2} / \mathrm{FiO}_{2}$ below 200 and pulmonary or extrapulmonary ARDS. All patients were on SB and their 28-day mortality rate remained below $27 \%$, not different from that reported in the general ARDS population undergoing invasive mechanical ventilation [19].

\section{Conclusions}

Data on the induction of VILI under spontaneous breathing are still controversial and those on patients without an endotracheal tube are substantially lacking. Whether or not the SB represents the real cause of VILI remains uncertain.

An important distinction should be made between mild, moderate and severe ARDS. While the experimental and clinical data are in favour of the beneficial effects of spontaneous breathing in the milder forms of ARDS, at present there is a consensus on its potential danger in severe lung injuries, due to the lack of volume control and the potential increase of the transalveolar pressures, both conditions capable of inducing VILI. The time course of the syndrome and its recovery deeply influence the ICU admission and mechanical ventilation. Over this period the effects of SB could be from "safe and protective" to "worsens and harmful".

Received: 29 June 2016 Accepted: 3 August 2016

Published online: 10 January 2017

\section{References}

1. Marini JJ (2011) Spontaneously regulated vs. controlled ventilation of acute lung injury/acute respiratory distress syndrome. Curr Opin Crit Care. 17(1):24-29

2. Mascheroni D, Kolobow T, Fumagalli R, Moretti MP, Chen V, Buckhold D (1988) Acute respiratory failure following pharmacologically induced hyperventilation: an experimental animal study. Intensive Care Med 15(1):8-14

3. Grasso F, Engelberts D, Helm E, Frndova H, Jarvis S, Talakoub O et al (2008) Negative-pressure ventilation: better oxygenation and less lung injury. Am J Respir Crit Care Med 177(4):412-418

4. Xia J, Zhang H, Sun B, Yang R, He H, Zhan Q (2014) Spontaneous breathing with biphasic positive airway pressure attenuates lung injury in hydrochloric acid-induced acute respiratory distress syndrome. Anesthesiology 120(6):1441-1449

5. Wrigge H, Zinserling J, Neumann P, Muders T, Magnusson A, Putensen C, Hedenstierna G (2005) Spontaneous breathing with airway pressure release ventilation favors ventilation in dependent lung regions and counters cyclic alveolar collapse in oleic-acid-induced lung injury: a randomized controlled computed tomography trial. Crit Care 9(6):R780-R789

6. Yoshida T, Uchiyama A, Matsuura N, Mashimo T, Fujino Y (2012) Spontaneous breathing during lung-protective ventilation in an experimental acute lung injury model: high transpulmonary pressure associated with strong spontaneous breathing effort may worsen lung injury. Crit Care Med 40(5):1578-1585

7. Yoshida T, Uchiyama A, Matsuura N, Mashimo T, Fujino Y (2013) The comparison of spontaneous breathing and muscle paralysis in two different severities of experimental lung injury. Crit Care Med 41(2):536-545

8. Dreyfuss D, Saumon G (1998) Ventilator-induced lung injury. Am J Respir Crit Care Med 157(1):294-323

9. Slutsky AS, Ranieri VM (2014) Ventilator-induced lung injury. N Engl J Med 370(10):980

10. Bellani G, Grasselli G, Teggia-Droghi M, Mauri T, Coppadoro A, Brochard L, Pesenti A (2016) Do spontaneous and mechanical breathing have similar effects on average transpulmonary and alveolar pressure? A clinical crossover study. Crit Care 20(1):142

11. Yoshida T, Roldan R, Beraldo MA, Torsani V, Gomes S, De Santis RR, Costa EL, Tucci MR, Lima RG, Kavanagh BP, Amato MB. Spontaneous effort during mechanical ventilation: maximal injury with less positive endexpiratory pressure. Crit Care Med. 2016;44(8):e678-e688

12. L'Her E, Deye N, Lellouche F, Taille S, Demoule A, Fraticelli A, Mancebo J, Brochard L (2005) Physiologic effects of noninvasive ventilation during acute lung injury. Am J Respir Crit Care Med 172(9):1112-1118

13. Antonelli M, Conti G, Rocco M, Bufi M, De Blasi RA, Vivino G, Gasparetto A, Meduri GU (1998) A comparison of noninvasive positive-pressure ventilation and conventional mechanical ventilation in patients with acute respiratory failure. N Engl J Med 339(7):429-435

14. Bellani G, Laffey JG, Pham T, Fan E, Brochard L, Esteban A, Gattinoni L, van Haren F, Larsson A, McAuley DF, Ranieri M, Rubenfeld G, Thompson BT, Wrigge H, Slutsky AS, Pesenti A, LUNG SAFE Investigators, ESICM Trials Group. Epidemiology, patterns of care, and mortality for patients with acute respiratory distress syndrome in intensive care units in 50 countries. JAMA. 2016;315(8):788-800. doi:10.1001/jama.2016.0291

15. Antonelli M, Conti G, Esquinas A, Montini L, Maggiore SM, Bello G, Rocco M, Maviglia R, Pennisi MA, Gonzalez-Diaz G, Meduri GU (2007) A multiplecenter survey on the use in clinical practice of noninvasive ventilation as a first-line intervention for acute respiratory distress syndrome. Crit Care Med 35(1):18-25

16. Patel BK, Wolfe KS, Pohlman AS, Hall JB, Kress JP (2016) Effect of noninvasive ventilation delivered by helmet vs face mask on the rate of endotracheal intubation in patients with acute respiratory distress syndrome: a randomized clinical trial. JAMA 315(22):2435-2441. doi:10.1001/ jama.2016.6338

17. Jaber $S$, Lescot $T$, Futier E, Paugam-Burtz C, Seguin P, Ferrandiere $M$, Lasocki S, Mimoz O, Hengy B, Sannini A, Pottecher J, Abback PS, Riu B, Belafia F, Constantin JM, Masseret E, Beaussier M, Verzilli D, De Jong A, Chanques G, Brochard L, Molinari N, NIVAS Study Group. Effect of noninvasive ventilation on tracheal reintubation among patients with hypoxemic respiratory failure following abdominal surgery: a randomized clinical trial. JAMA. 2016;315(13):1345-53. doi:10.1001/ jama.2016.2706

18. Frat JP, Thille AW, Mercat A, Girault C, Ragot S, Perbet S, Prat G, Boulain T, Morawiec E, Cottereau A, Devaquet J, Nseir S, Razazi K, Mira JP, Argaud L, Chakarian JC, Ricard JD, Wittebole X, Chevalier S, Herbland A, Fartoukh M, Constantin JM, Tonnelier JM, Pierrot M, Mathonnet A, Béduneau G, Delétage-Métreau C, Richard JC, Brochard L, Robert R, FLORALI Study Group, REVA Network. High-flow oxygen through nasal cannula in acute hypoxemic respiratory failure. N Engl J Med. 2015;372(23):2185-96

19. Lemiale V, Mokart D, Resche-Rigon M, Pène F, Mayaux J, Faucher E, Nyunga M, Girault C, Perez P, Guitton C, Ekpe K, Kouatchet A, Théodose I, Benoit D, Canet E, Barbier F, Rabbat A, Bruneel F, Vincent F, Klouche K, Loay K, Mariotte E, Bouadma L, Moreau AS, Seguin A, Meert AP, Reignier J, Papazian L, Mehzari I, Cohen Y, Schenck M, Hamidfar R, Darmon M, Demoule A, Chevret S, Azoulay E, Groupe de Recherche en Réanimation Respiratoire du patient d'Onco-Hématologie (GRRR-OH) (2015) Effect of noninvasive ventilation vs oxygen therapy on mortality among immunocompromised patients with acute respiratory failure: a randomized clinical trial. JAMA 314(16):1711-1719 